\title{
Drought Monitoring in the Dry Zone of Myanmar using MODIS Derived NDVI and Satellite Derived CHIRPS Precipitation Data
}

\author{
Rishiraj Dutta ${ }^{1}$ \\ ${ }^{1}$ United Nations Economic and Social Commission for Asia and the Pacific (UNESCAP), Rajadamnern Nok Ave, \\ Bangkok-10200, Thailand
}

Correspondence: Rishiraj Dutta, Space Application Section, UNESCAP, Bangkok, Thailand. E-mail: rishi.journal@gmail.com

Received: January 9, 2018 Accepted: February 2, 2018 Online Published: February 25, 2018

doi:10.5539/sar.v7n2p46

URL: https://doi.org/10.5539/sar.v7n2p46

\begin{abstract}
Drought has become an increasingly frequent phenomena around the globe causing negative impacts on ecosystems, agriculture, and socio-economic conditions. While efforts have been underway for developing effective monitoring and risk management measures, it still remains a challenge in countries like Myanmar where access to observed and near real time data is a constraint. This study therefore, tries to derive correlations between MODIS Normalized Difference Vegetation Index (NDVI) and Climate Hazards Group InfraRed Precipitation with Station (CHIRPS) data to see if some empirical relationships can be established. Statistical analysis showed that strong correlation $\left(\mathrm{R}^{2}=0.74\right.$ and 0.82$)$ exist between NDVI and CHIRPS data indicating that vegetation stress conditions observed in the Dry Zone of Myanmar is due to insufficient precipitation conditions. The analysis also showed that the region had faced with three extreme conditions during the period from 1981-2015 with 2014 and 2015 being the extreme event. It further concluded that NDVI and CHIRPS could provide near real time information on vegetation stress situations of the Dry Zone of Myanmar.
\end{abstract}

Keywords: CHIRPS, drought, Dry Zone, MODIS, NDVI

\section{Introduction}

Droughts are recurring climatic events bringing about significant shortages in water, losses to economy and agricultural production. It is a slow onset disaster whose exact triggering point is difficult to determine. Shift in the rainfall pattern and prolong dryness help determine the onset of droughts and its impacts. Moreover, with the growing population, the demand for water and natural resources have also grown overtime leading to significant stress on the environment. Therefore, the need for proper quantification of drought impacts and monitoring and reporting of droughts became critically important. The use of satellite derived information becomes important to monitor vegetation stress conditions. Agricultural sector is most affected by the onset of drought as it is highly reliable on weather, climate and soil moisture (Sruthi and Aslam, 2015). The role of remote sensing and GIS in agricultural drought detection, assessment and management is therefore, becoming crucial as they provide up to date information in different range of spatial and temporal scales which is hectic and time consuming when done by traditional methods such as Field Survey, and sampling questionnaires (Thenkabail et al. (2004); Arshad et al. (2008); Hasan and Saiful, (2011)). The vegetation index has been considered by numerous scientists as one of the important parameters for mapping of agricultural fields, estimating weather impacts, calculating biomass, crop yield, drought conditions and determining the vigor of the vegetation (Sruthi and Aslam, 2015; Tucker et al., 1982; Justice et al., 1985; Hielkema et al., 1986; Dabrowska-Zielinska et al., 2002; Narasimhan and Srinivasan (2005), Chakraborthy and Sehgal (2010).

There are different kinds of vegetation indices currently available but the most, simplest, efficient and commonly used vegetation index is the Normalized Difference Vegetation Index (NDVI). The index developed by Tucker in 1979 , provides information on vegetation health and density. NDVI is calculated from the visible and near infrared light reflected from vegetation (NASA Earth Observatory). It has also been widely employed to describe spatiotemporal characteristics of land use and land cover including percent vegetation coverage (Kaufmann et al., 2003). Cunyong et al., 2011, employed NDVI as an indicator to estimate percent vegetation cover in heterogeneous topographical features and vegetation cover in mid-west china.

With drought having been directly related to precipitation, the use of satellite derived precipitation products have 
become amply important to get near-real time information. Conventionally, rain gauge records provide the most accurate means to obtain information about the rainfall climate, however, sparse spatial networks within a country and incomplete rainfall records results in leaving a country unobserved making it a challenge to provide up-to-date rainfall records for drought monitoring. The problem is further exacerbated by the high spatial variability associated with convective rainfall at the daily time-step that makes a rain gauge measurement only representative of rainfall over several square kilometers surrounding the gauge. Such limitations have elevated the importance of satellite derived rainfall estimates with full spatial coverage needed specifically for agriculture and drought monitoring. Studies have revealed that satellite derived rainfall products are useful for drought and flood monitoring and overcomes the problem of sparse, unevenly distributed and erratic rain gauge observations (Tote et al., 2015). Although there are limitations of satellite derived rainfall estimates, but it still overcome the need for near-real time rain gauge observations which are typically sparse, poorly spatially distributed, and reported sporadically. Algorithms to derive rainfall from satellite observations are either based on thermal infrared (TIR) bands, which measure cloud top temperature that can be used to identify convective rainfall in the Inter-Tropical Convergence Zone (ITCZ), or on passive microwave (PM) sensors (Tote et al., 2015). However, over the years many satellite based rainfall estimate products have been developed. Empirical algorithms, calibrated using rain gauge data, are used to derive rainfall rates from observed signals, but parameters can vary in space and time. Some of the algorithms are exclusively based on thermal Infrared (TIR) data from geostationary satellites such as Meteosat-8 and Geostationary Operational Environmental Satellite (GOES), while others are based only on microwave data from the Special Sensor Microwave Imager (SSM/I), Tropical Rainfall Measuring Mission (TRMM), or the Advanced Microwave Sounding Unit (AMSU). Some products combine both TIR and passive microwave (PM) imagery and include ground-based rainfall observations or numerical weather prediction (NWP) model information. Multi-sensor algorithms have been reported to reduce the inherent sampling errors of satellite estimates.

While there is an ever growing collection of satellite-based datasets capable of providing near-real time estimates, only a handful of publicly available high resolution satellite-based datasets are providing historic data (at least 30 years) at the daily time-step and updated in real time or near-real time (Maidment et al., 2017). The precipitation data called Climate Hazards Group InfraRed Precipitation with Station data version 2.0 (CHIRPS) is one such data that provide rainfall estimates at $5 \mathrm{~km}$ resolution and is available from 1981 onwards.

While regions like the Dry Zone in Myanmar has been under prolonged stress conditions for years, the need for constant monitoring of stress conditions is critical. With satellite based rainfall estimates such as the CHIRPS available at daily interval for more than thirty years period, near-real time monitoring of drought conditions is possible for Government agencies such as Department of Meteorology and Hydrology and Ministry of Agriculture to monitor time-to-time conditions on the ground.

Therefore, this study tries to derive correlations between MODIS Normalized Difference Vegetation Index (NDVI) and globally calibrated CHIRPS precipitation data to see if these relations can be used as an early warning for drought in the Dry Zone of Myanmar.

\section{Materials and Methods}

\subsection{Study Area}

The Dry Zone of Myanmar covers more than 54,000 km of area encompassing 58 townships spanning from lower Sagaing region, to the western and central parts of Mandalay region and most of Magway region (Myanmar Information and Management Unit) (Figure1). The region accommodates approximately one-quarter of the country's population. Situated in the shadow of the Rakhine mountain range, the Dry Zone receives limited rains compared to country averages. The climate however, is not homogenous across the area with conditions ranging from semi-arid (and even arid) in certain areas to semi-humid in others. Dry spells during the rainy season are frequent, but their intensities vary geographically and over time. Insufficient rainfall is not only the potential hazard, but decreasing forest cover and soil erosion have placed the communities at greater risk of localized flash floods during times of heavy rain. The Dry Zone is particularly affected by food security issues. 


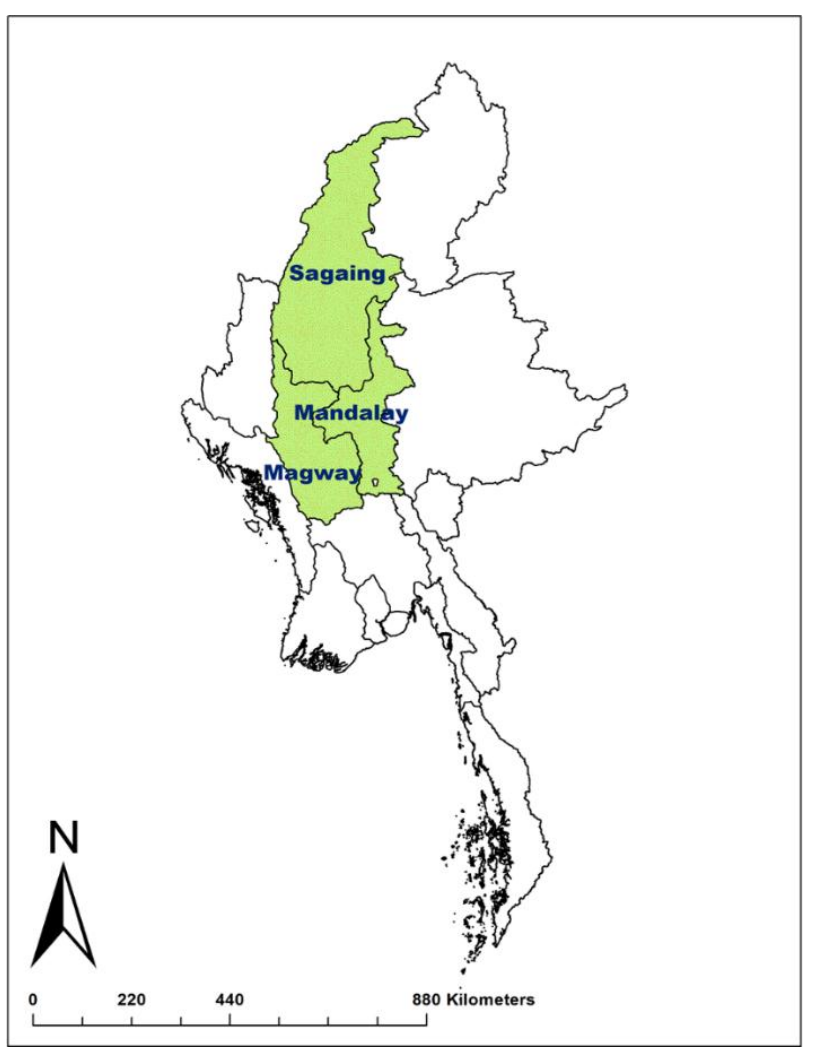

Figure 1. Map showing the study area

\subsection{Data Used}

The study uses the MODIS based NDVI data and Climate Hazards group InfraRed Precipitation with Stations (CHIRPS) data to derived correlations between MODIS NDVI and precipitation. The data used was from Mandalay Region of the Dry Zone.

\subsubsection{MODIS Normalized Difference Vegetation Index (NDVI)}

MODIS vegetation indices are available at sixteen day intervals and at multiple spatial resolutions. It provides consistent spatial and temporal coverage of comparisons of vegetation canopy greenness, a composite property of leaf area, chlorophyll and canopy structure. It produces two sets of data NDVI and Enhanced Vegetation Index (EVI). The MODIS NDVI data provides continuity with NOAA AVHRR NDVI time series record for historical and climate applications. The data is available at $250 \mathrm{~m}$ resolution and provides sixteen day composites covering the vegetation conditions for the entire globe.

\subsubsection{Climate Hazards Group InfraRed Precipitation with Stations (CHIRPS)}

Climate Hazards Group InfraRed Precipitation with Station (CHIRPS) data is a thirty plus year quasi-global rainfall dataset created in collaboration with scientists at the U.S. Geological Survey (USGS) Earth Resources Observation and Science (EROS) Center in order to deliver reliable, up to date, and more complete datasets for a number of early warning objectives (such as trend analysis and seasonal drought monitoring). Spanning $50^{\circ} \mathrm{S}-50^{\circ} \mathrm{N}$ (and all longitudes), starting in 1981 to near-present, CHIRPS incorporates $0.05^{\circ}$ resolution satellite imagery with in-situ station data to create gridded rainfall time series for trend analysis and seasonal drought monitoring. The creation of CHIRPS has supported drought monitoring efforts by the USAID Famine Early Warning Systems Network (FEWS NET). The CHIRPS data used for this study is from Mandalay region close to its weather station.

\subsection{Methods}

The method applied for this study includes extraction of MODIS derived NDVI and extraction of CHIRPS data for the Mandalay Region of Myanmar. This is followed by deriving the correlation between NDVI and Precipitation data and understanding the moisture stress conditions in the region. 


\subsubsection{Extraction of NDVI from MODIS Data}

The Normalized Difference Vegetation Index (NDVI) is used to identify vegetation conditions (Dutta, 2013). The NDVI is traditionally used to extract vegetation abundance from remotely sensed data (Tucker, 1979). It divides the difference between reflectance values in the visible red and near infrared wavelengths by the overall reflectance in those wavelengths:

$$
N D V I=(N I R-V R) /(N I R+V R)
$$

where, NIR and VR are reflectance in near-infrared and visible red regions, respectively.

NDVI for this study was generated from the MODIS data for the Mandalay Region of the Dry Zone of Myanmar for the year 2014 and the monthly means of the NDVI is calculated. The year 2014 is considered in this study, as this was an El Nino year with extreme drought conditions experienced in the Southeast Asia.

\subsubsection{Extraction of CHIRPS data for the Dry Zone of Myanmar}

The CHIRPS data for the Mandalay Region of the Dry Zone of Myanmar was downloaded from the SERVIR ClimateSERV tool for the period from 1981-2015 and the total yearly trend was generated. Considering the year of 2014 and 2015 as the El Nino year, the total monthly precipitation was derived using the daily precipitation data for the said period.

\subsubsection{Statistical Analysis}

A simple linear regression analysis was performed on the available data to establish the relationship between MODIS NDVI and CHIRPS. Whereas CHIRPS was considered an independent variable, the MODIS NDVI was considered a dependent variable during the analysis.

$$
N D V I_{d z}(t)=\beta_{0}+\beta_{1} \text {. CHIRPS }(t)+\varepsilon(t)
$$

where, $N D V I_{d z}(t)$ is the NDVI value in time ' $t$ ' for Dry Zone ' $d z$ ' and CHIRPS is the precipitation value in time ' $t$ '.

\section{Results}

\subsection{Analyzing Precipitation Trends Using CHIRPS}

The yearly precipitation trend was analyzed using CHIRPS data for the period from 1981-2015 (Figure 2). The trend shows that Mandalay region of Dry Zone has received the maximum precipitation in the year 2006 with over $1065 \mathrm{~mm}$ recorded as the total annual precipitation received. However, the overall historical trend suggest that the region has received comparatively less precipitation throughout that is less than $1000 \mathrm{~mm}$. The trend also suggest that the region has experienced three dry spells with lowest precipitation, the first being 1982 with over $433 \mathrm{~mm}$ of precipitation, the second being 2014 with over $285 \mathrm{~mm}$ of precipitation and the third being 2015 receiving over $319 \mathrm{~mm}$ of precipitation. These results highlights that the region has been experiencing continuous dry periods over the years. 2014 and 2015 being considered as El Nino year, the region has experienced extreme dry spells throughout the years.

\subsection{NDVI- Rainfall Relationships}

Applying the linear regression to the data, strong linear relationships was observed between NDVI and CHIRPS precipitation data for the period 2014 and 2015 with $\mathrm{R}^{2}$ values of 0.74 and 0.82 respectively (Figure $3 \mathrm{a}$ and $3 \mathrm{~b}$ ). The analysis have shown that NDVI is directly proportional to that of rainfall. With the decrease in rainfall, the vegetation stress tends to increase indicating prevalence of dry conditions. With the increase in rainfall, the vegetation conditions tends to become normal with improved NDVI values. Further plotting the NDVI values with rainfall and months together suggests that NDVI tends to depend on the existing moisture conditions in the area (Figure $4 \mathrm{a}$ and $4 \mathrm{~b}$ ). The yearly rainfall trend also indicates that the area receives scanty rainfall and experience dry conditions. 


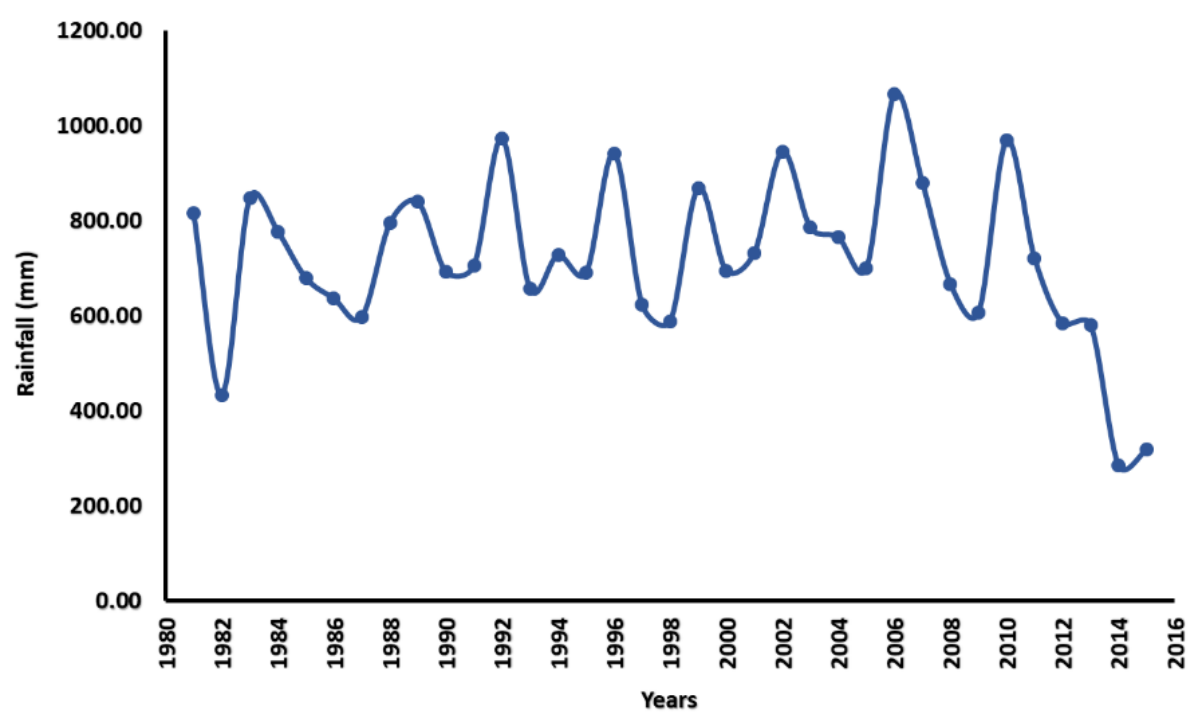

Figure 2. Chart showing the rainfall pattern of the Mandalay Region of the Dry Zone of Myanmar from 1981-2016

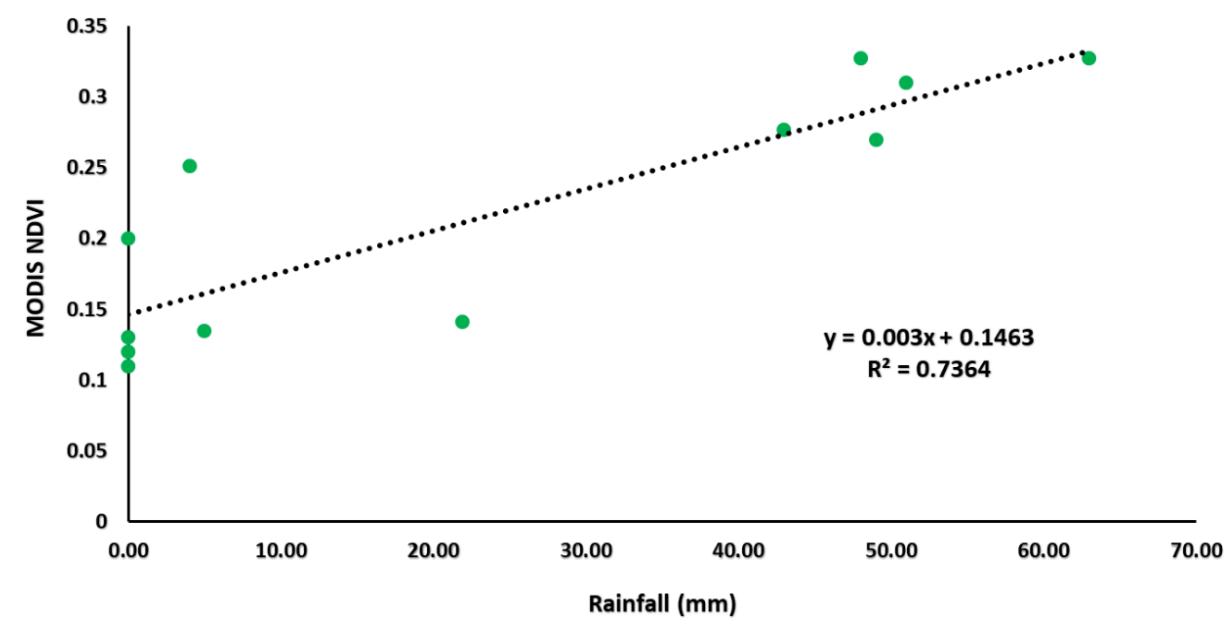

Figure 3a. Chart showing the NDVI-Rainfall Scatterplot of Mandalay Region of the Dry Zone of Myanmar for 2014

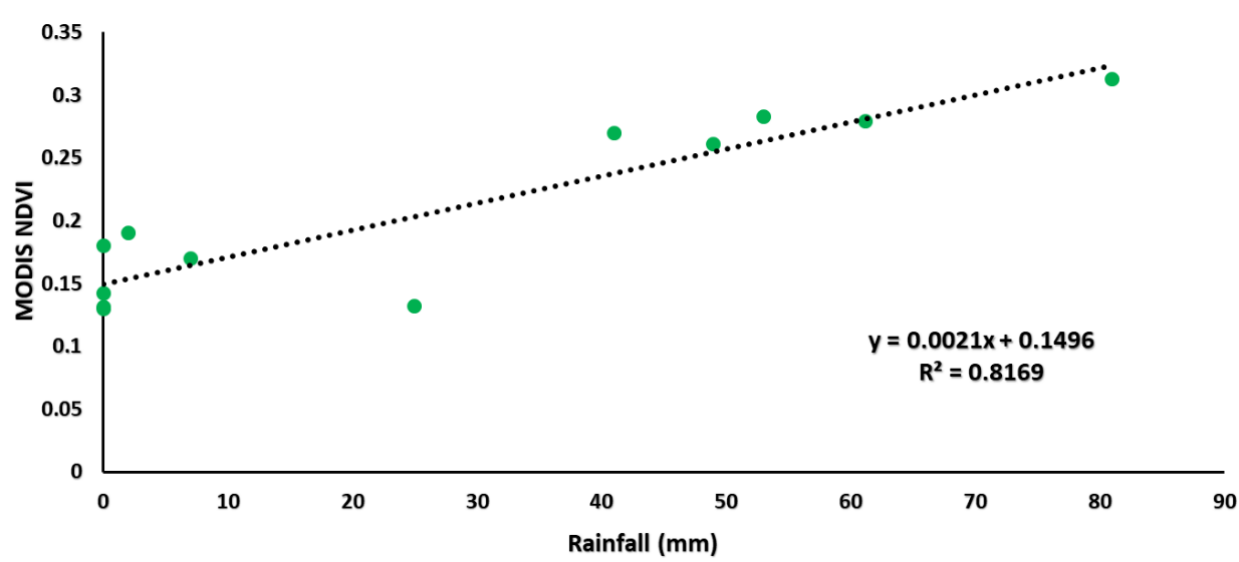

Figure 3b. Chart showing the NDVI-Rainfall Scatterplot of Mandalay Region of the Dry Zone of Myanmar for 2015 


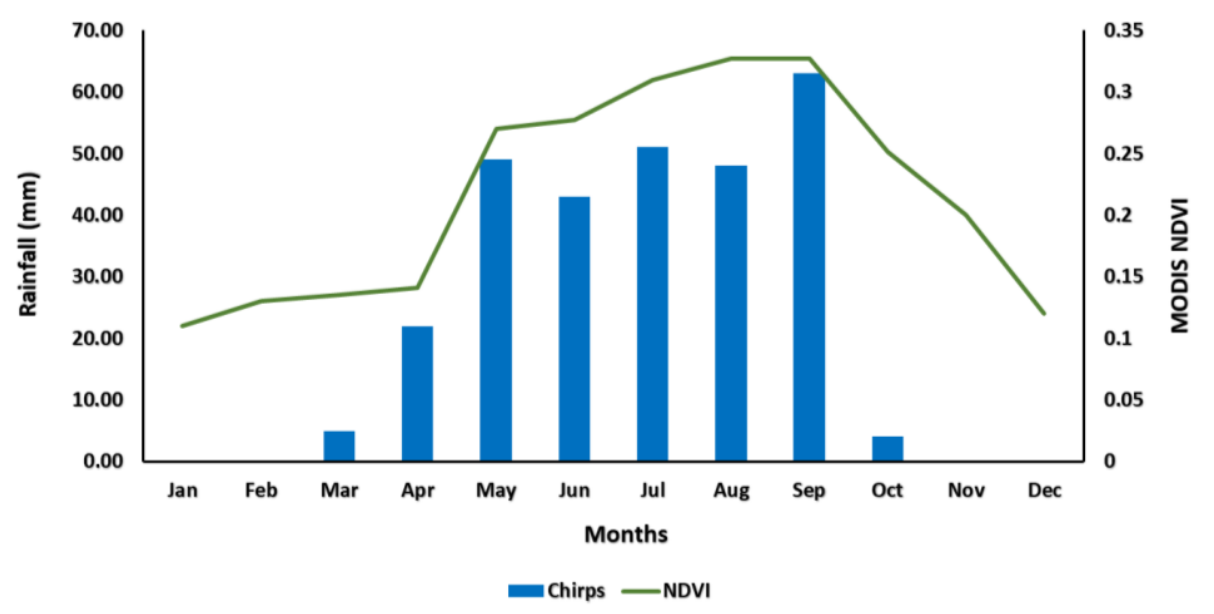

Figure 4a. Chart showing the NDVI-Rainfall Relationship of Mandalay Region of the Dry Zone of Myanmar for 2014

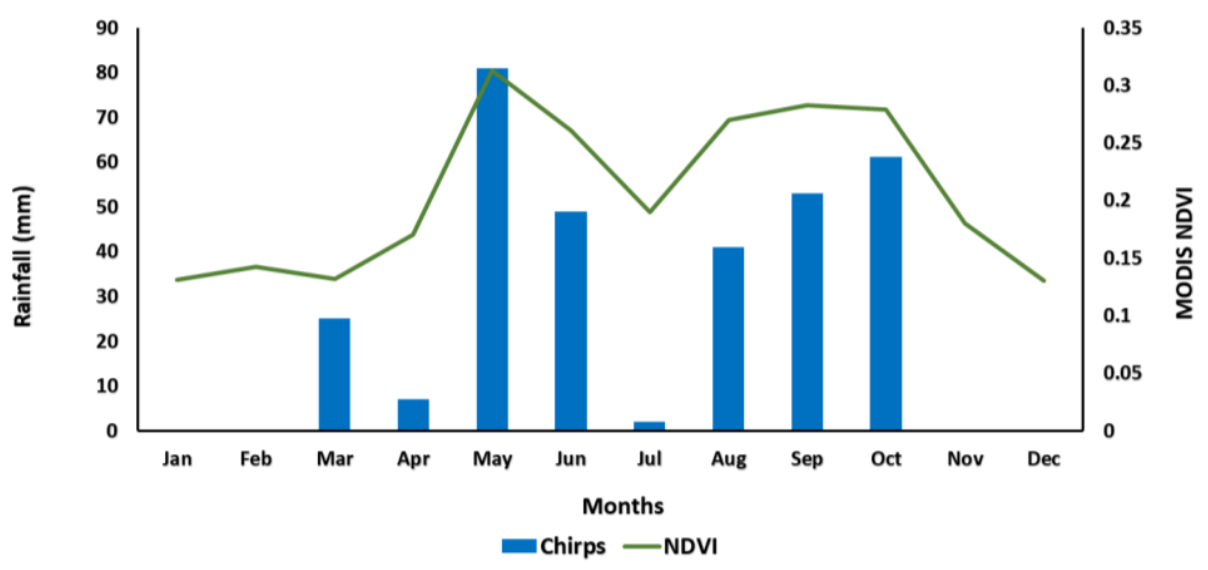

Figure 4b. Chart showing the NDVI-Rainfall Relationship of Mandalay Region of the Dry Zone of Myanmar for 2015

\section{Discussions}

The study has shown that fluctuations in NDVI data for Mandalay region is mainly due to fluctuations in precipitation amounts and the yearly trends derived from the NDVI and CHIRPS precipitation data suggest that the region has been experiencing continuous dry conditions. It is to be noted here that satellite observations potentially provide much greater spatial and temporal coverage of drought conditions. Any relationships derived between NDVI and precipitation data would greatly enhance future drought monitoring efforts. Gu et al., 2008 highlights that satellite derived Normalized Difference Vegetation Index (NDVI) has played an important role for vegetation drought monitoring. Their research suggest that accurately monitoring and assessing near-real time vegetation drought conditions in the United States may provide decision makers with accurate, synoptic, and timely information for effective drought planning and mitigation and reduce economic losses. Higher NDVI values reflect greater vigor and photosynthetic capacity (or green-ness) of vegetation canopy, whereas lower NDVI values for the same time period are reflective of vegetative stress resulting in chlorophyll reductions and changes in the leaves' internal structure due to wilting. Research have also shown that soil moisture is a critical component in land surface-atmospheric processes (Brubaker and Entekhabi, 1996 and Gu et al., 2008), and prolonged soil moisture deficits often lead to drought-induced vegetation stress. The results from the current study also indicates to such prevailing conditions. According to Department of Meteorology and Hydrology, Government of Myanmar, water shortage is most severe in Ayeyarwaddy, Sagain, Yangon, Mandalay, and Bago regions. The Drought Annual Report of DMH states that severe to moderate drought occurred during 2012 and 2013 while the extreme drought conditions were experienced during 2014 and 2015 which is also considered to be the El Nino period. The major impacts due to drought in these regions includes agricultural fields, farmers, 
drinking water scarcity and social, economic, health, public, livestocks and environment of Myanmar. According to NASA Earth Observatory, NDVI is considered as an indicator of drought. It states that NDVI values overtime can be averaged to establish the normal growing conditions for vegetation in a given period for a given time of the year. Whether a plant growth is significantly more or less productive due to lack of precipitation would allow researchers to decide whether such conditions are to be labelled as drought. NDVI as a drought monitor could provide information on vegetation stress conditions. Time series NDVI images would prove to be a powerful tool for near-real time monitoring of stress conditions in the Mandalay region. Moreover, with the availability of MODIS NDVI data as sixteen day composite would provide decision makers with effective monitoring of drought situations in the region as well as serving as a tool for early warning mechanism. NDVI data would allow agricultural managers in Mandalay region to analyze vegetation conditions for all season from NDVI or vegetation maps, NDVI curves and figures that anticipate major variations in productivity and potential harvest. While NDVI data can be used for monitoring vegetation conditions, the correlations derived from NDVI and precipitation data would allow decision makers and agriculture managers to understand the dependency of NDVI on rainfall variations. The derivation of NDVI time series charts can help understand the development of vegetation condition on a long-term basis (Gross, 2005).

Drought is a recurrent event across the world having spatial and temporal characteristics that varies significantly from one region to another (Singh, 2003). In every drought monitoring practice more emphasis is given to meteorological drought (simple absence/deficit of rainfall from the normal) as it is the first to occur and other droughts are consequent to it (Goshu et al., 2017). If the precipitation deficit continues for a longer period, all the other drought happens one after the other (Hao et al., 2017). Many countries consider that drought monitoring system is one of most effective ways for reducing drought damages by early drought detection and issuing warnings (Boken et al., 2005). It is always difficult to choose the most appropriate drought index as not all drought indices can be applied to all geographical and climatic regions.

To monitor meteorological drought in a particular area, precipitation data is the primary requirement that can be obtained either from gauge collected precipitation data or from satellite rainfall products. However, it is always seen that weather stations within a country are sparsely distributed and in most cases remains non-accessible to general public. This is one of the major constraints that most countries faces when it comes to accessibility of observed meteorological data. Moreover, incidents such as droughts becomes very difficult to monitor if there is uneven or limited distributions of weather stations within a country.

While early warning systems have become an important entity for hazards such as droughts and floods, the availability of near real-time information for monitoring such conditions is crucial. Although such systems are available today but there still lies challenges in terms of getting access to observed meteorological data which is a very critical component for an effective drought early warning system. While the challenges still remains, the alternative ways to monitor and analyze drought conditions is through the use of available global products that can help provide information to decision makers at the shortest possible time. It is also well understood that some of these global products would require further calibration depending on the conditions for which they are being used.

With the advancement of remote sensing technology a variety of high-resolution satellite derived precipitation products are currently available at the global scale. Climate Hazard Infrared Precipitation Station Data (CHIRPS) rainfall products is one among them that have made daily rainfall data available from 1981 onwards to present. The benefits of CHIRPS rainfall product is that it is available with a relatively longer time period (more than 35 years) having a near-global coverage with high spatial (0.050) and temporal (daily) resolution (Mou et al., 2017). Evaluation of the CHIRPS rainfall data for Mandalay Region with that of the NDVI showed good agreement for monthly and yearly time scale. The availability of CHIRPS data also addresses the data gaps in areas which are inaccessible or where meteorological stations are sparsely distributed.

Therefore, using satellite derived NDVI, the correlations are developed to assess the potential of CHIRPS rainfall product and investigating historical droughts across Mandalay Region of Myanmar. However, it is still expected that there is a likely possibility of some variations in the results when compared with the observed rainfall data. This comparison could not be done in this study due to non-accessibility of observed meteorological data. CHIRPS being a globally calibrated data might require to be further calibrated and validated to Myanmar conditions using observed precipitation data. The current study however showed that relationships can be established from NDVI and CHIRPS data indicating that such information could serve as a good indicator for drought monitoring and early warning.

With the advantages of CHIRPS data available at daily interval from 1981 onwards to present, the analysis 
allowed us to understand the precipitation trend of the Mandalay Region of the Dry Zone. Considering its large spatial coverage, it is presumed that CHIRPS can fill the data gaps that might exist in areas where the availability of weather station is sparse or areas which are inaccessible. The CHIRPS data can also be used with monthly aggregation of daily data from the period 1981-2015 that overlaps the period of ground based rainfall data and can provide rainfall information from areas with complex terrain where the rainfall station densities are limited. Therefore it is understood that CHIRPS can be used for near-real time monitoring of precipitation conditions of a particular area and is a good estimate for regions where availability of precipitation data is sparse.

Satellite data such as MODIS available at $250 \mathrm{~m}$ resolution, is a good resolution for a large areas like the Mandalay Region of Dry Zone of Myanmar. Although the drought indices derived from remote sensing data have been used to monitor meteorological or agricultural drought, there are no indices that can suitably reflect the comprehensive information of drought from meteorological to agricultural aspects (Du et al., 2012). But the advantages of using MODIS data is that images are available on a daily recurrent period with broader swath and therefore provides the possibility of cloud free real time data for drought or vegetation stress monitoring. The NDVI data generated from MODIS can be available either daily or as sixteen day composites. The spatial and temporal consistency is of great value as it can detect changes in vegetation conditions over time. NDVI being the most commonly used vegetation index, is also capable of providing near-real time indicator of onset, extent, intensity and duration of vegetation stress. NDVI has been used extensively for vegetation stress monitoring and could make significant contribution towards developing an operational drought index capable of allowing decision makers to make appropriate and timely decisions in response to drought. The current study uses MODIS NDVI data for the year 2014 and 2015 to understand the vegetation stress conditions as these two years are considered to be El Nino years. Correlations were developed using MODIS NDVI and CHIRPS data of 2014 and 2015 and strong relations could be observed between NDVI and CHIRPS. According to Department of Meteorology and Hydrology (DMH), Government of Myanmar, the severe El Nino impacts have brought down Myanmar's agricultural yield significantly resulting in food insecurity during 2014 and 2015. It is indicated that the side effects continues to last even after the El Nino period got over. The country's agricultural sector was affected by extremely high temperature and water shortage, leading to lower yield compared to the previous years. Based on the impact from the El Nino event of 2014 and 2015, vegetation stress conditions from satellite derived MODIS NDVI and CHIRPS precipitation data were observed. The analysis showed that relationships exists between NDVI and CHIRPS data indicating that with the decrease in rainfall the stress conditions increases. These could be seen from the lower NDVI values derived from the satellite data. Establishment of such relationships also confirms that with the variation in rainfall, the NDVI also varies.

\section{Conclusions}

The study concluded that strong correlation exists between MODIS NDVI and CHIRPS precipitation data indicating that with the variations in rainfall, NDVI also varies. The study also showed that the Mandalay Region of the Dry Zone of Myanmar is rainfed as the overall precipitation pattern suggest that the region has experienced dry conditions over the years. It showed that 2014 and 2015 is considered the driest year due to the severe impact of El Nino with the region receiving about 285 and $319 \mathrm{~mm}$ of rainfall respectively. It further showed that globally calibrated data such as MODIS NDVI and CHIRPS can be a good indicator to be used for near-real time monitoring of drought conditions and can serve as an early warning to decision makers to prepare and respond to drought situations. Although CHIRPS data proved to be a reliable data source for such analysis, but further calibration of the data with observed rainfall data needs to be done in order to be able to address any under- or over-estimation of the data. Lastly, the study concludes that time series analysis of observed and satellite derived precipitation data is essential to understand the stress conditions for effective monitoring of the Region.

\section{Acknowledgement}

The research is self-conducted based on the available data from SERVIR ClimateSERV.

\section{References}

Arshad, S., Morid, S., Reza, M. M., \& Agha, A. M. (2008). Development of Agricultural Drought Risk Assessment Model for Kermanshah Province (Iran), using Satellite Data and Intelligence Methods. Option Mediterrianeennes, Series A: No. 80.

Boken, V. K., Cracknell, A. P., Heathcote, \& R. H. (2005). Monitoring and Predicting Agricultural Drought: A Global Study. Oxford University Press, New York, pp. 472.

Brubaker, K. L., and D. Entekhabi (1996). Analysis of Feedback Mechanisms in Land-Atmosphere Interaction. 
Water Resources Research, 32(5), 1343-1357. https://doi.org/10.1029/96WR00005

Chakraborthy, A., \& Sehgal, V.K. (2010). Assessment of Agricultural Drought Using MODIS Derived Normalized Difference Water Index. Journal of Agricultural Physics; 10, 28-36.

Cunyong, J., Tijiu, C., \& Xiaohui, Y. (2011). Topography-based Modeling to Estimate Percent Vegetation Cover in Semi-Arid Mu Us Sandy Land, China. Computers and Electronics in Agriculture; 64(2), 133-139.

Dabrowska-Zielinska K., Kogan F., Ciolkosz A., Gruszczynska M., \& Kowalik W. (2002). Modelling of Crop Growth Conditions and Crop Yield in Poland using AVHRR Based Indices. International Journal of Remote Sensing; 23(6), 1109-1123. https://doi.org/10.1080/01431160110070744

Dutta, R. (2013). Monitoring Green Leaf Tea Quality Parameters of Different TV Clones Grown in Northeast India using Satellite Data. Food Chemistry, 139, 689-694. https://doi.org/10.1016/j.foodchem.2013.01.086

Du, L., Tian, Q., Yu, T., Meng, Q., Jancso, T., Udvardy, P., \& Huang, Y. (2012). A Comprehensive Drought Monitoring Method Integrating MODIS and TRMM Data. International Journal of Applied Earth Observation and Geoinformation, 23, 245-253. https://doi.org/10.1016/j.jag.2012.09.010

Goshu, E. L., Upadhyaya, S., \& Ramsankaran, R. (2017). Meteorological Drought Monitoring Across Different Rainfall Regimes of Ethiopia Using CHIRPS V2 Rainfall Data. $38^{\text {th }}$ Asian Conference on Remote Sensing, (ACRS 2017), New Delhi, India.

Gross, D. (2005). Monitoring Agricultural Biomass using NDVI Time Series. Food and Agriculture Organization (FAO).

Gu, Y., Hunt, E., Wardlow, B., Basara, J. B., Brown, J. F., \& Verdin, J. P. (2008). Evaluation of MODIS NDVI and NDWI for Vegetation Drought Monitoring Using Oklahoma Mesonet Soil Moisture Data. Geophysical Research Letters, 35(22). 116. https://doi.org/10.1029/2008GL035772

Hasan, M., \& Saiful Islam, A. K. M. (2011). Drought Assessment Using Remote Sensing and GIS in North-West Region Of Bangladesh, $3^{\text {rd }}$ International Conference on Water \& Flood Management (ICWFM-2011).

Hielkema, J. U., Prince, S. D., \& Astle, W. L. (1986). Rainfall and Vegetation Monitoring in the Savanna Zone of Democratic Republic Sudan using NOAA Advanced Very High Resolution Radiometer. International Journal of Remote Sensing, 7, 1499-1514. https://doi.org/10.1080/01431168608948950

Hao G., Anming B., Tie, L., He, F. N., Kurban, A., \& De Maeyer, P. (2017). Meteorological Drought Analysis in the Lower Mekong Basin Using Satellite-Based Long-Term CHIRPS Product. Sustainability, 9, 901. https://doi.org/10.3390/su9060901

Justice, C. O., Townshend, J. R. G., Holben, B. N., \& Tucker, C. J. (1985). Analysis of the Phenology of Global Vegetation using Meteorological Satellite Data. International Journal of Remote Sensing, 6, 1271-1318. https://doi.org/10.1080/01431168508948281

Kaufmann, R. K., Zhou, L. M., Myneni, R. B., Tucker, C. J., Slayback, D., Shabanov, N. V., \& Pinzon, J. (2003). The Effect of Vegetation on Surface Temperature: A Statistical Analysis of NDVI and Climate Data. Geophysical Research Letters, 30, 21-47. https://doi.org/10.1029/2003GL018251

Maidment, R. I., Grimes, D., Black, E., Tarnavsky, E., Young, M., Greatrex, H., Allan, R. P., Stein, T., Nkonde, E., Senkunda, S., \& Alcántara, E. M. U. (2017). A New, Long-Term Daily Satellite-based Rainfall Dataset for Operational Monitoring in Africa. Nature (Scientific Data), 4, 170063.

Mou, L. T., Tan, K. C., Chua, V. P., \& Chan, N. W. (2017). Evaluation of TRMM Product for Monitoring Drought in the Kelantan River Basin, Malaysia. Water, 9(1), 57.

Narasimhan, B., \& Srinivasan, R. (2005). Development and Evaluation of Soil Moisture Deficit Index and Evapotranspiration Deficit Index for Agricultural Drought Monitoring. Agricultural and Forest Meteorology, 133, 69-88. https://doi.org/10.1016/j.agrformet.2005.07.012

Singh, S. (2003). Drought and its Management in India. Short Term Course on Drought Analysis and Management, IIT, Roorkee, SS, pp. 1-15.

Sruthi, S., \& Aslam, M. A. (2015). Agricultural Drought Analysis using the NDVI and Land Surface Temperature Data: A Case Study of Raichur District. Aquatic Procedia, 4, 1258-1264. https://doi.org/10.1016/j.aqpro.2015.02.164

Thenkabail, P. S., Gamage, M. S. D. N., \& Smakhtin, V. U. (2004). The Use of Remote-Sensing Data for Drought Assessment and Monitoring in Southwest Asia. International Water Management Institute Research 
Report 85, PO Box 2075, Colombo, Sri Lanka.

Tote, C., Patricio, D., Boogaard, H., van der Wijngaart, R., Tarnavsky, E., \& Funk, C. (2015). Evaluation of Satellite Rainfall Estimates for Drought and Flood Monitoring in Mozambique. Remote Sensing, 7(2), 1758-1776. https://doi.org/10.3390/rs70201758

Tucker, C. J. (1979). Red and Photographic Infrared Linear Combinations for Monitoring Vegetation. Remote Sensing of Environment, 8, 127-150. https://doi.org/10.1016/0034-4257(79)90013-0

Tucker, C. J., Gatlin, J., Schnieder, S. R., \& Kunginos, M. A. (1982). Monitoring Large Scale Vegetation Dynamics in the Nile Delta and River Valley from NOAA AVHRR data. Proceedings of the Conference on Remote Sensing of Arid and Semi-Arid Lands, Cairo, Egypt, pp. 973-977.

Wardlow, B. D., Anderson, M. C., \& Verdin, J. P. (2012). Remote Sensing of Drought. Taylor \& Francis Group.

\section{Copyrights}

Copyright for this article is retained by the author(s), with first publication rights granted to the journal.

This is an open-access article distributed under the terms and conditions of the Creative Commons Attribution license (http://creativecommons.org/licenses/by/3.0/). 